\title{
Innovative-oriented development of AIC complex as an economic priority development vector of the Far Eastern Federal District
}

\author{
Lyubov Pashina ${ }^{1}$, Svetlana Pastushenko ${ }^{1}$, and Valerii Reimer ${ }^{1, *}$ \\ ${ }^{1}$ Far Eastern State Agrarian University, 86, Polytechnic st., Blagoveshchensk, 675005, Russia
}

\begin{abstract}
The transition of the agro-industrial complex of the Far Eastern Federal District to innovative-oriented development objectively enforces the activation of innovative and investment processes, as well as ensuring effective management of innovative development as a single complex of interrelated economic processes. The specific territorial zoning of the region's AIC requires differentiation of the innovative development strategies of its individual sectors in accordance with the certain conditions of their functioning. The research is based on the study and generalization of scientific approaches to the issues of innovativeoriented development of the AIC, taking into account various factors: territoriality, zonality, economic potential, etc. The article formulates a set of provisions underlying the development of the innovative-oriented development concept of the AIC of the region. There was determined the set of strategic goals of its innovative development regarding the specifics of the subjects. The purpose of research is to develop a conceptual approach to innovative-oriented development of AIC of the region, in appliance with its specifications.
\end{abstract}

\section{Introduction}

The structural complexity and heterogeneity of the agro-industrial complex (AIC) of the Far Eastern Federal District (FEFD), a significant differentiation of subjects according to climatic conditions, economic potential and the level of development of agricultural production, the relatively low investment attractiveness of the agricultural sector compared with extractive industries, the lag in technical and technological proliferation, the narrowed ability of economic entities in the agrarian sector to conduct expanded reproduction, the persisting price disparity in agricultural products and goods providing agricultural production (fuels and lubricants, mineral fertilizers, chemical plant protection products, fixed assets, etc.) all these significantly inhibit innovative activity of production and territorial systems that form the basis of agricultural production in the Far East regions.

The low effective demand for innovative developments and technologies imposes significant restrictions on the quality parameters of the innovative entities growth rate,

\footnotetext{
* Corresponding author: valer-ken@mail.ru
} 
which perform functions of innovative generating, monitoring their market, their expertise, selection and adaptation to the conditions of the Far Eastern region. The gap between producers of innovations and their consumers determines the infrastructural fragmentation of the innovative system of the AIC of the whole country and individual regions.

\section{Materials and Methods}

The research is based on the study and generalization of scientific approaches to the issues of innovative-oriented development of the AIC, taking into account various factors: territoriality, zonality, economic potential, etc. The purpose of research is to develop a conceptual approach to innovative-oriented development of AIC of the region, in appliance with its specifications.

\section{Results}

For a long time, the agricultural sector of the Russian economy has undergone significant stagnation. Recently, in this industry, it has been possible to achieve constant and steady growth. According to the Ministry of Agriculture of the Russian Federation, in 2018 the growth of agricultural production amounted to $2.3 \%$, taking into account the food industry and the production of drinks. Agricultural exports increased by $20.0 \%$, to a record $\$ 24.8$ billion. According to Deloitte, the share of AIC in the structure of gross domestic product in 2018 amounted to $4.1 \%$. The AIC of the Far Eastern Federal District makes an insignificant contribution to the total volume of crop and livestock production from the all-Russian one, which amounted to $3 \%$ and $4 \%$, respectively, in 2019. The low share of the Far Eastern Federal District in agricultural production in Russia is mainly due to the fact that agricultural production in the Far East is carried out in difficult climatic conditions, due to which individual subjects of the region have extremely limited opportunities for agricultural production.

An assessment of the conditions for the functioning of the agro-industrial complex of the Far Eastern Federal District made it possible to identify factors limiting its development potential. The main ones include: unfavorable natural and climatic conditions, significant territorial differentiation of the constituent entities of the okrug according to the conditions of agricultural production, the focal nature of agriculture, a critically low level of development of the material and technical base of economic entities of the agrarian sphere of the okrug, a decrease in the already extremely low fertility of productive land, a low level of efficiency in the use of natural fodder lands, the predominance in the agricultural structure of the district of small forms of economy of a consumer type with a low level of marketability of production, a low level of efficiency of agriculture and its investment attractiveness, low competitiveness of agricultural producers in the district, underdevelopment of production and market infrastructure, a steady decline the size of the rural population against the background of the deformation of the demographic structure, a high level of logistics and transport costs, a low standard of living the population of the district and the unbalanced structure of its nutrition, etc.

An assessment of the available reserves for increasing the efficiency of agricultural production suggests that even on the basis of the use of traditional technologies with adequate government support, economic entities in the agricultural sector can increase production by $20-25 \%$, but it is possible to reach a qualitatively new level only if an innovative model of industry development is implemented., the transition to which is possible only if a number of restrictions are overcome, determined by the peculiarities of 
the organization of innovative processes in the modern agro-industrial complex of Russia. These features include:

- deformed agrarian structure of the national economy, characterized by the predominance in a number of agricultural sectors of non-commodity forms of agricultural production, weakly receptive to innovations, and small agribusiness entities that do not have the financial ability to acquire and use innovations;

- the lack of structures that would allow consolidating the interests of individual agricultural producers in the search, financing of development and use of innovations;

- the indistinctness of the state agrarian policy and the low level of state support for agricultural producers, which do not allow the modernization of the material and technical base and ensure the financial stability of their functioning;

- a significant impact of natural and climatic conditions on the level of localization of the use of innovative solutions and the need for additional costs for the adaptation of a significant part of them for various natural and climatic zones;

- limited range of agricultural products due to natural and climatic conditions and the historically established system of location of agricultural production;

- a higher level of innovation risks in the agricultural sector due to its significant dependence on poorly controlled natural and climatic conditions of management;

- reduction of the innovative potential of Russian agricultural science due to illconsidered reform of the system of fundamental and applied scientific research;

- low competitiveness of domestic innovative solutions in the field of seed production, genetics of farm animals, technical support of promising technologies, computerization of production processes, etc .;

- degradation of labor resources in the agricultural sector due to the outflow of qualified personnel to urban areas, limiting the use of sophisticated equipment, psychological unpreparedness of the rural population to the need for technical and technological changes;

- destruction of the system of initial vocational training of workers for economic entities of the agricultural sector in conditions of a sharp increase in the complexity of machines used in production and equipment, etc.

The organization of innovative activity in the agro-industrial complex as a form of orderly interaction of its subjects is carried out within the framework of the innovation system of the agro-industrial complex, taking into account the impact of the institutional environment and the state as an objectively necessary coordinator and regulator of innovation processes

In this regard, the transfer of the AIC of the Far Eastern Federal District to the innovative vector of development is unavoidable and objectively requires the activation of innovative and investment processes, as well as ensuring the management of innovative ontogenesis as a unified complex of interrelated economic bases that unite all subjects of innovative and investment activity and ensure the continuity of all stages of innovative process implementation: from the generation of ideas to the launch of a new product to the market.

It is obvious that the activation of innovative processes in the AIC should be carried out both towards the development of the entire innovative environment of local territorial formation at various levels, and towards improving the innovation system of the territorialindustrial complex based on its industry specification and innovative potential [1].

Defining the key directions and growth points of innovative activity of economic entities of the agricultural economy sector and stirring up of innovative processes in agricultural sector we should take into account the fact, that innovation is a natural element of scientific and technological progress in agriculture, which main directions in recent years are: complex mechanization, automation and electrification of production processes, 
scientifically-based and rational chemical provision of agricultural production; land reclamation and increasing its productivity; development of resource-saving technologies and biologization of agriculture; selection of high-yielding and sustainable varieties of crops; breeding livestock with high productive potential; specialization deepening and increasing concentration of production based on the development of cooperative relations and agro-industrial integration; improvement of forms and methods of organization and labor motivation; deepening the integration of agriculture with other sectors of economy [24].

The long-term format of innovative development, its high capital intensity and significant investment needs, high level of competition and necessity to assess the economic feasibility of choosing one or another system development trajectory, objectively determine the need to develop a concept and strategy for innovative development.

The pronounced zonal territoriality of AIC of the Far Eastern Federal District objectively requires differentiation of innovative development strategies of both individual sectors of agro-industrial production and individual territorial-production entities on the assumption of specific conditions of their functioning. At the same time, there are directions for the use of innovations that are common to any region of Russia. These include: the introduction of commodity, technological (product), resource, organizational, economic and socio-economic innovations [5].

Based on the level of development of AIC of the Far Eastern region, its innovative and investment-economic potentials, the high degree of differentiation of territories according to the conditions of agricultural production, it is proposed to identify as priority areas for intensifying innovative processes: stimulating innovative activity, building up the innovative potential of producers and consumers of innovations, infrastructure development of innovative system.

The stimulation of innovative activity must be carried out as part of the development strategy of an innovative-oriented AIC. The absence of such a strategy creates uncertainty in the innovation environment associated with the uncertainty of the state's position towards the transformation of the AIC to the innovative development path. The targeted programs should be developed exactly in accordance with the accepted strategy that reflect the priority directions for the development of AIC and ensure the concentration of resources at constitutive growth points of the agricultural economy within the framework of national and most significant regional innovative projects with their adequate financial support from federal and regional budgets [6-9].

In addition, the State should form an institutional and economic mechanism for soft loans, priority financing of innovative projects and provision of substantial tax preferences to business entities of innovative activity. A mandatory measure to stimulate the generation of innovations has to be the development of a grant system and structural optimization of research funding in accordance with the priorities of innovative ontogenesis, and for consumers of innovation - ensuring equal access to innovative resources and technologies of large, medium and small agribusiness entities.

It is rationally selected tools to stimulate innovation activity that can provide fundamental changes in the innovative environment and give a new impulse to the development of agribusiness in the Far Eastern Federal District.

The second way of intensification of innovative processes is related to building up the innovative potential of innovation producers. In this area, priority is given to the formation of a government order for fundamental scientific research and the development of applied innovative solutions. It is the state that should influence the formation of the innovation portfolio and balance the demand for innovations with their supply.

In addition to government order, it should be used a system of grants as a financing tool for research and development, ensuring the maintenance of the necessary level of 
competition in the market of innovative developments. The question of adequacy of the existing scientific research organization system to the needs of the real sector of the economy is becoming increasingly acute. On the basis of agricultural research institutes and higher education institutions, it is necessary to create regional and interregional centers for the innovative development of the AIC, which should become drivers of innovative processes and create conditions for the concentration of efforts in the priority areas for the development of regional agribusiness.

The integration of research institutions and universities will ensure the complexity of scientific developments and the ability to transfer innovations to consumers with a full package of parallel services (staff training, implementation and maintenance of innovations, consulting, etc.). Particular attention should be paid to their material and technical base for research, development and subsequent implementation of innovative products. The process of cooperation between research organizations and universities as innovation developers with direct manufacturers of innovative products is possible.

An important condition for increasing the innovative potential for innovation producers is the stirring up of scientific research and overcoming inertial activities in agricultural science associated with the loss of stable links between science and production due to decrease in the effective demand for scientific developments from the economic entities of the agricultural sector $[3,10]$.

In conditions of low efficiency of innovation development system of the AIC of the Far Eastern Federal District on the basis of proposed Innovative Development Centers, it is necessary to create structures that implement the functions of monitoring the market of domestic and foreign innovations and a preliminary assessment of the prospects for their use in territorial-industrial complexes, taking into account the specifics of the agricultural production of certain regions.

A key element of the system of measures to increase the innovative potential of economic entities in the agricultural sector of the Far Eastern region is to increase the efficiency of agricultural production. In addition to mobilizing the domestic reserves of agricultural producers, the available directions for creating the prerequisites for building up their innovative potential include the development of integration and cooperation communications, participation in industrial unions and associations, and joining clustertype structures.

With the improvement of financial situation of economic entities and the increase in their sensibility to innovations, there will be formed saluberogenic conditions to establish stable relations with scientific institutions and organizations. Thereby, the development of agribusiness in the Far Eastern Federal District involves the simultaneous implementation of several models: models for the development of cooperation and infrastructure support (for households with a low level of marketability), models for the restoration and modernization of the material and technical base (for unprofitable farms and farms with a low level of profitability), models of complete and creative imitation of innovations (for sustainable effective and financially stable business entities) and a model of pure innovations (for business entities ready to become pioneers in the production of new types of products, in the transition to fundamentally new agricultural technologies, etc.).

As an independent direction of the activation of innovation processes in the AIC of the Far Eastern Federal District, we can mark out the infrastructural development of the innovation system. Today, there is an acute problem of financial support for all innovative activities and, above all, the implementation of innovative projects. In developed countries, the core of the financial support system for innovations is venture funds and companies, but in the Far East, as in Russia as a whole, agriculture is not an object of venture investment, which requires the search for alternative sources of financing for innovations. 
The main tasks of development of innovation infrastructure of the agricultural sector of the Far East are: ensuring the interaction of producers and consumers of innovations, studying the demand for innovations and informing agricultural producers about the proposal of innovative developments, the formation of agro-technological park structures and support systems for innovations, improving the quality of staffing for innovative activities, developing an innovative insurance system risks.

In our opinion, during substantiating the concept of innovative development, it is necessary to focus on the following elements: justification of the strategic goals of innovative development; choosing a model of innovative development; localization of territories of innovative development; identifying priority areas of innovation and their types; selection of innovations in accordance with the objectives of system development; the formation of an innovation management system; substantiation of the mechanism for implementing the innovation development strategy.

The concept design of innovative development should proceed from the fact that given limited resources and significant territorial differentiation in the ontogenesis of regionallevel economic systems, it seems impossible to ensure high rates of development simultaneously in all territories and in all sectors [11-17].

There are objective prerequisites for the justification of localization of territories of active innovative development with the identification of industries and spheres that are drivers of the growth of territorial and territorial-sectoral entities of various levels. Moreover, we need to have a clear vision in which area of innovation (technological and product solutions, management processes, personnel and organizational structure, performance management and information systems, etc.) we should focus according the development potential of the economic system, strategic goals and development models.

In our opinion, the design of development concept of an innovative-oriented agribusiness in the Far Eastern Federal District should be based on the following postulates:

- Significant territorial differentiation of the Far Eastern Federal District according to the climatic and economic conditions, the level of development of agriculture and the structure of the agricultural sector requires the development of original strategies for each of the entities;

- Uneven development of agricultural production sectors does not allow for their simultaneous transformational subrogation to the path of innovation-oriented development;

- To implement the economic policy of transferring the AIC to an innovative-oriented vector of development, it is necessary to create a network of regional centers for innovation development, combining the scientific potential of entities and being the core of the formation of the innovation infrastructure system with the participation of the state and the business community;

- Limited resources issue requires the determination of development priorities and concentration of efforts at growth points, ensuring the maximum multiplicative effect in each subject;

- A major share in the production of agricultural products of small forms of management, poorly susceptible to innovations, requires the implementation of specialized procedures that provide them comfort conducting agribusiness and create conditions for involving economic resources in the production process that are unattractive for large and medium enterprises;

- The advantages of large-scale production can be most effectively implemented in those sectors of agriculture, in which production technologies are close to industrial, and can minimize the environmental and climatic risks;

- Increase in agricultural production should be accompanied by adequate development of production and market infrastructure; 
- The focal nature of agriculture necessitates the territorial dispersal of infrastructure facilities oriented towards servicing, first of all, small entities of the agricultural sector of the economy.

A significant differentiation of climatic conditions necessitates the allocation of three conditionally territorial zones of agricultural production: the southern and northern zones of the Far East and central part of Yakutia.

The main agricultural producers and processing enterprises are concentrated in the southern zone. The prospects for the entities of this zone are related to increasing soybean production and expanding the capacity for its deep processing, changing the structure of grain farming, expanding the area of corn sown for grain, and increasing the production of potatoes and open ground vegetables.

The increase in production of feed grain and high-protein soybean processing products is the basis for the formation of the feed base for poultry and pig farming, which development is possible through the construction of large complexes and creation of appropriate infrastructure (feed mills, slaughterhouses and meat processing enterprises, etc.).

The development of dairy cattle breeding will occur both at the expense of small family dairy farms and large agricultural enterprises. But the prospects for the construction of mega-farms with a livestock of more than 1000 heads are limited by the high cost of one cattle-place and the risks of concentration of the cattle in unstable epizootic conditions.

In the northern territories, agricultural production will have a distinct specialization related to the territorial areas of indigenous peoples and their national types of agricultural production - reindeer husbandry, fishing, gathering wild plants, etc. The dominance of small business forms, for the purpose of implementing innovations, requires the formation of their adequate infrastructure support through the development of supply-procurement cooperation, cooperation on land cultivation, provision of feed, etc.

A promising direction for the northern zone is large-scale meat reindeer husbandry in the centers of highly productive natural forage land. In conditions of steadily growing demand for reindeer husbandry products, this industry can become a driver for agricultural development in the northern territories of the Far Eastern Federal District, and become a supplier of venison and related products to other regions of Russia and for export.

There are certain prospects for the development of dairy and beef cattle breeding in households and peasant (farmer) households. The development of pig and poultry production is constrained by a shortage of feed resources and the high cost of production.

For Central Yakutia, with more than 700 thousand hectares of hayfields and pastures, the task should be set to stabilize and further increase of dairy cattle. It is possible to increase the efficiency of using natural fodder lands through the development of beef cattle breeding and herd horse breeding. As a promising direction in the development of livestock raising, we can consider increasing the production capacities of poultry farms in both egg and meat sectors. Crop production in this zone will be focal in nature, focused on local consumption [2].

The implementation of an innovative scenario for the development of the agro-industrial complex of the Far Eastern Federal District requires the consolidation of the efforts of regional authorities, scientific and educational institutions, public organizations (industry unions, associations of manufacturers of certain types of products, etc.), development institutions and directly economic entities of the agro-industrial complex.

In accordance with the strategy, a set of measures is being developed aimed at the formation of an innovative environment that allows solving the tasks defined by the strategy of innovative development: justification of priority areas of scientific research is carried out, an effective model of interaction between science and production is selected, directions and an algorithm for the development of innovative infrastructure are 
determined, and efficiency is assessed the use of unique and imitating innovations available to manufacturers, an assessment of the innovative potential of individual industries is given, taking into account the specifics of the region and possible options for the territorial location of innovative industries.

Taking into account the innovative potential of the branches of the agro-industrial complex, regional target programs are being developed, with a description of the necessary scientific, resource, technological, regulatory and information support. Obviously, when developing targeted programs, a systematic approach should be used, which allows for the comprehensive development of the agro-industrial complex, taking into account the distribution of a limited amount of financial resources in accordance with the established development priorities.

The transition of the regional agro-industrial complex and individual industries to an innovation-oriented development path is carried out through the implementation of specific innovation and investment projects carried out within the framework of regional target programs. The number of participants in these programs and the scale of innovation and investment projects are determined based on their volume of budgetary support, the level of innovation potential of specific industries, the potential efficiency of projects, the level of competitiveness of manufactured products, the material and technical base of innovation consumers and their financial condition. The participation of the state in co-financing the activities of participants in targeted programs implies strict control over the targeted use of financial resources allocated from budgets of various levels on the basis of constant monitoring of a system of indicators reflecting the state of implementation of innovation and investment projects. In addition, the expected increase in the production of certain types of agricultural products should be ensured by the adequate development of the infrastructure for their transportation, storage and processing. According to experts, due to the provision of optimal conditions for transportation of storage of products, its losses can be reduced by 2.5-3.5 times, and an increase in the depth of its processing will increase the cost of products of the regional agro-industrial complex by almost 2 times.

It should be noted that budgetary co-financing of innovation and investment projects can reach $25-30 \%$ of investment costs, while the bulk of investment resources will be borrowed and attracted funds. In the context of low investment attractiveness of almost all branches of agricultural production in the Far East, the problem of financing high-risk investment-intensive projects with rather long payback periods is acute. In this regard, government support is required for the development of two special institutions: venture financing and insurance of innovative risks [13].

In the context of the relatively low effectiveness of the innovation activity of the domestic research system, in order to overcome the technical and technological backwardness of the agro-industrial complex in the next 3-5 years, economic entities of the agrarian sector will have to focus on the use of imitating innovations in the formation of an industry order for the development of domestic scientists in those areas that will allow obtain sustainable competitive advantages and improve the efficiency of the regional agroindustrial complex [13].

\section{Conclusion}

The main objective of development concept of innovative-oriented agribusiness in the Far Eastern Federal District is to determine the strategic goals of its functioning based on the regional specification, the level of development of agricultural production and the place of territorial-industrial complexes in the regional economy. These goals include:

- Providing the population of the region with quality food, taking into account the changing nutritional structure; 
- Achieving the optimum of agrarian structure in regional economy, focused on the maximum use of the agrarian potential of region and ensuring employment and selfemployment of the rural population;

- Involvement in the economic turnover of unused productive land and creation of conditions for their use;

- Formation of the agricultural sector, providing high profitability and attractiveness of agricultural labor;

- Creating comfortable living conditions for the rural population and development of social infrastructure in order to maintain economic and social control over rural areas, etc.

The transition of AIC of the Far Eastern Federal District to an innovative-oriented path of development is possible only with an adequate level of state support for the integrated development of the agricultural sector. Otherwise, the outflow of the rural population will begin to accelerate, and the reduction in agricultural production will sharply reduce the level of food security in the region and will require the allocation of significant funds to provide the Far East with food.

\section{References}

1. V.V. Reimer, A.V. Ulezko Conceptual and methodological approaches to the formation of an innovative system within agricultural food sector, Voronezh: Bulletin of Voronezh State Agrarian University, 4(47), 196-207 (2015)

2. V.V. Reimer, A.V. Ulezko Conceptual approach to developing a strategy for the innovative development of the agricultural sector in the F ar East, 1, 20-26 (2016)

3. I.S. Sandu Organizational and economic aspects of the formation of innovative systems in agribusiness, ed I.S. Sandu. Moscow: VNIIESKH, 169 (2012)

4. A.V. Ulezko, N.G. Nechaev, I.S. Sokovykh, A.V. Klimov Economic entities of the agrarian sector: resource support and innovative development. (2013)

5. N. Gorshkova, L. Grigoryeva, P. Perekhodov, E. Shkarupa, A. Arkannikov Informational and analytical support for integration of agro-industrial enterprises in Russia, Russia and the European Union. Development and Perspectives.399-405 (2017)

6. A. Ulezko, V. Reimer, O. Ulezko Theoretical and methodological aspects of digitalization in agriculture. Proceedings from IOP Conference Series: Earth and Environmental Science. Moscow. Russia, IOP Publishing, 274. 012062 (2019)

7. T.V. Savchenko On the prospects of agro-industrial clusters formation, Research Journal of Pharmaceutical, Biological and Chemical Sciences, 5, 1681-1686 (2014)

8. K.S. Ternovykh, N.G. Nechaev, A.A. Izmalkov Agro-industrial integrated formations: state and development prospects, Monograph VSAU, 245 (2013)

9. E.V. Ivanova, E.Y. Merkulova Qqualitative changes of the state regulation of reproduction processes in agriculture based on digital technologies. Quality-Access to Success, 19(S2), 130-134 (2018)

10. M. Kosolapova Digital agricultural economic system and electronic agricultural development intensification, Studies in Computational Intelligence. 826. 663-674 (2019)

11. S. Kreneva, E. Tsaregorodtsev, Y. Sredina, Agro-industrial complex in the conditions of development of digital society as the instrument of economic development of the region. Proceedings from SGEM 18: International Multidisciplinary Scientific GeoConference Surveying Geology and Mining Ecology Management, (2018) 
12. N.N. Yurina, The digitalization of agriculture as a priority direction of russian economic's development. Proceedings from EpSBS CIEDR 2018: The European Proceedings of Social $\&$ Behavioural Sciences. Future Academy. Veliky Novgorod, Russia, Future Academy (2019).

13. V.V. Reimer, A.V. Ulezko Innovative-oriented development of the agroindustrial complex of the Far East: monograph 348 (2016) 348

14. K.S. Ternovykh, N.G. Nechaev Development of the integrated structures in the agroindustrial complex: problems of solution stages, Econ. of agricult. and proc. companies, 8,53-56 (2012)

15. O. Borisova, L. Abramova, L. Zageeva, E. Popkova, I. Morozova Role of agricultural clusters in provision of food security, Europ. Res. Studies J., 3, 18, 287-298 (2015)

16. T.A. Pechenegina Fformation of the economic clusters as the impulse of economic growth, Int. J. of Appl. Busin. and Econ. Res., 14, no. 14, 727-734 (2016)

17. V. V. Yankovskaya, et al, Some problems arising in ensuring the right to information of employees Journal of Legal, Ethical and Regulatory Issues 22(4), 8 (2019) 